\title{
Formation of the Liquid Crystalline Glassy Phase and Cold Crystallization of a New Crystal Form from the Glassy Phase for Thermotropic Liquid Crystalline Polyether
}

\author{
Miwa MuraKami, Hiroyuki IsHIDA, Hironori KAJI, and Fumitaka HoRII ${ }^{\dagger}$ \\ Institute for Chemical Research, Kyoto University, Uji, Kyoto 611-0011, Japan
}

(Received July 3, 2003; Accepted October 7, 2003)

\begin{abstract}
The formation of the liquid crystalline (LC) glassy phase and phase transitions including cold crystallization associated with this phase have been investigated for main-chain thermotropic LC polyether (EDMB-10), which is composed of 3,3'-dimethyl-4,4'-biphenyl units as mesogen and 10 methylene sequences as spacer, by mainly using DSC, wide angle X-ray diffractometry, and solid-state ${ }^{13} \mathrm{C}$ NMR spectroscopy. When the sample is quenched from the isotropic melt to ice-water, the LC glassy phase is really produced as suggested by the previous finding that the liquid crystallization temperature is almost independent of the cooling rate whereas the crystallization temperature rapidly decreases with increasing cooling rate. The liquid crystalline glass thus formed is found to undergo cold crystallization above $T_{\mathrm{g}}$ and to produce a new type of crystal form (form $\beta$ ) which is significantly different in structure from form $\alpha$ ordinarily crystallized on cooling from the isotropic melt through the nematic phase. In particular, the highest crystallinity of form $\beta$ can be obtained by annealing the LC glass at $130^{\circ} \mathrm{C}$ for $30 \mathrm{~min}$-about $2 \mathrm{~d}$ and then quenching to $0{ }^{\circ} \mathrm{C}$. This fact suggests that the stable nematic phase associated with the crystallization of form $\beta$ may appear on rapid heating around $130^{\circ} \mathrm{C}$. In addition, form $\alpha$ is also crystallized even on heating when the LC glass is annealed at $132-134{ }^{\circ} \mathrm{C}$ and also quenched to $0^{\circ} \mathrm{C}$, implying the appearance of the stable nematic phase preferentially producing form $\alpha$ at this temperature range. Additional phase transitions are also observed for the form $\beta$ sample with the highest crystallinity and their origins are briefly discussed.

KEY WORDS Liquid Crystalline Polymer / Liquid Crystalline Glass / Cold Crystallization / Nematic Phase / Solid-State ${ }^{13} \mathrm{C}$ NMR / Polyether / Conformation /
\end{abstract}

Various main-chain thermotropic liquid crystalline (LC) polymers have been developed for more than these two decades, and their phase transitions and structures in possible phases have extensively been investigated by calorimetry, microscopy, diffractometry, spectroscopy, and so on. ${ }^{1-6}$ However, the structure and dynamics at a molecular level are not fully understood in the respective phases and the detailed information is still limited about the relationship between the chemical structure and properties for the main-chain thermotropic LC polymers. The main reason of such difficulties may be due to thermal instability in the LC phase mostly appearing at higher temperatures and a lack of systematic investigations directly associated with the LC phase.

Recently we synthesized a new type of main-chain thermotropic LC polyether EDMB-10 (Scheme 1) with a simple chemical structure and found that the phase transitions associated with the nematic phase appear in the range of temperature less than $150{ }^{\circ} \mathrm{C}$ where most of analytical methods can be employed without any thermal changes in chemical structure of the sample. ${ }^{7,8}$ For example, we could investigate in detail the liquid crystallization and crystallization processes induced on cooling from the isotropic melt for the EDMB-10 sam-

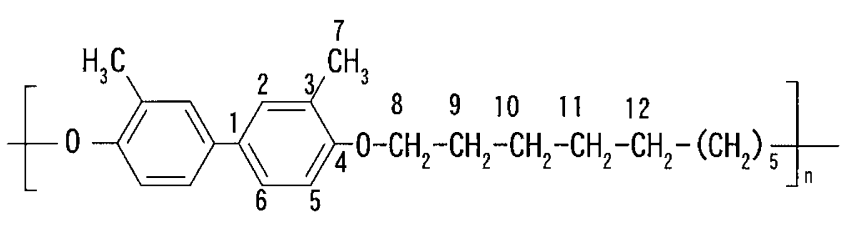

EDMB-10

Scheme 1.

ples with different molecular weights and also successfully characterized the spacer conformation and mesogen dynamics in the crystalline and noncrystalline regions for the sample crystallized from the isotropic melt through the nematic phase. Nevertheless, it is still difficult to produce the stable nematic phase for a certain period for EDMB-10 because the crystallization readily occurs from the nematic phase particularly at slower cooling rates.

In this paper, the formation of the LC glassy phase ${ }^{9}$ by quenching from the isotropic melt is first examined on the basis of the previous results ${ }^{8}$ of the dependencies of the liquid crystallization and crystallization on the cooling rate. Next, the cold crystallization is carried out at different temperatures by annealing the LC glass and a new type of crystal form (form $\beta$ ) is found to be produced in these cases whose structure is significantly

${ }_{\dagger}^{\dagger}$ To whom correspondence should be addressed (horii@scl.kyoto-u.ac.jp). 
different from that of the crystal form (form $\alpha$ ) which is ordinarily crystallized on cooling from the isotropic melt. Through these experiments, the possible appearance of the stable nematic phase is pointed out in the heating process although the temperature range for the phase is very limited around $130^{\circ} \mathrm{C}$.

\section{EXPERIMENTAL}

\section{Samples}

LC polyether EDMB-10 was synthesized by the polymerization of 3,3'-dimethyl-4,4'-dihydroxy-biphenyl and 1,10-dibromodecane in a two phase system containing each monomer in each phase using a phase transfer catalyst as previously described in detail. ${ }^{7}$ $M_{\mathrm{n}}$ s of the EDMB-10 samples thus obtained were determined to be $8000-21000$ by polystyrene-calibrated GPC.

\section{Polarizing Optical Microscopy}

Thermal phase transitions and texture changes were observed on a Nikon OPTIPHOT2-POL optical polarizing microscope equipped with a Linkam LK-600PM hot stage. Each powder-like sample was placed on a glass slide, covered with a glass cover slip, and heated or cooled under a nitrogen atmosphere on the hot stage at a rate of $10^{\circ} \mathrm{C} \mathrm{min}^{-1}$.

\section{Differential Scanning Calorimetry (DSC)}

DSC thermograms were measured for about $3 \mathrm{mg}$ of each sample under a nitrogen atmosphere at scanning rates of $1-10{ }^{\circ} \mathrm{C} \mathrm{min}^{-1}$ on a TA Instruments DSC2910 differential scanning calorimeter. The temperature was calibrated using indium. A first-order transition temperature was determined as a maximum or minimum of each transition peak.

\section{Wide-angle X-ray Diffractometry}

Wide-angle X-ray diffraction profiles were collected with a Rigaku RINT-2500 diffractometer equipped with a monochrometer $(\mathrm{Cu}-K \alpha$ radiation). The scanning range of the scattering angle $2 \theta$ was $2-45^{\circ}$ at a step of $0.02^{\circ}$ and a scan speed of $1.2^{\circ} \mathrm{min}^{-1}$.

\section{Solid-State ${ }^{13}$ C NMR Measurements}

Solid-state ${ }^{13} \mathrm{C}$ NMR measurements were performed at various temperatures on a Chemagnetics CMX200 spectrometer equipped with a JEOL variable temperature magic angle spinning (MAS) system operating at $50.0 \mathrm{MHz}$ under a static magnetic field of $4.7 \mathrm{~T} .{ }^{6-8,10-13}{ }^{1} \mathrm{H}$ and ${ }^{13} \mathrm{C}$ radio-frequency fields $\gamma B_{1} / 2 \pi$ were $62.5 \mathrm{kHz}$ in the cross polarization (CP) process and the ${ }^{1} \mathrm{H}$ decoupling field strength was re- duced by about $10 \%$. The contact time for the CP process was $1.0 \mathrm{~ms}$ and the recycle time after the acquisition of a free induction decay (FID) was $5 \mathrm{~s}$ throughout this work. The MAS rate was set to $3.8 \mathrm{kHz}$ to avoid the overlapping of spinning sidebands on other resonance lines. ${ }^{13} \mathrm{C}$ isotropic chemical shifts were expressed as values relative to tetramethylsilane $\left(\mathrm{Me}_{4} \mathrm{Si}\right)$ by using the $\mathrm{CH}_{3}$ line at $17.36 \mathrm{ppm}$ of hexamethylbenzene crystals as an external reference. ${ }^{13} \mathrm{C}$ spin-lattice relaxation times $\left(T_{1}^{\mathrm{C}}\right)$ were measured for some samples by using the CPT1 pulse sequence. ${ }^{14}$ The temperature calibration was carried out by the ethylene glycol method developed for solid-state MAS measurements. ${ }^{15-17}$

\section{RESULTS AND DISCUSSION}

\section{Formation of the LC Glassy Phase}

Figure 1 shows a polarizing optical microscope photo image taken at $4{ }^{\circ} \mathrm{C}$ for the powder-like EDMB-10 sample immediately after it was quenched from the isotropic melt to ice-water. Typical nematic Schlieren texture is clearly observed in the quenched sample. Similar but much smaller-size Schlieren texture was also observed in the nematic phase for the EDMB-10 sample slowly cooled from the isotropic phase, ${ }^{7}$ but such nematic texture almost disappeared after the crystallization was induced on cooling. Therefore, the result shown in Figure 1 suggests that the LC glassy phase may be formed in the quenched sample at lower temperatures as a result of the suppression of crystallization by quenching. ${ }^{9}$ This possibility may be reasonably understood because the phase transition temperature from the isotropic melt to the nematic phase hardly depends on the cooling rate whereas the crystallization temperature greatly decreases with increasing cooling rate, as previously reported. ${ }^{8}$

To confirm the real formation of the LC glassy phase and possibly subsequently occurring phase transitions such as the glass-LC transition or cold crystallization, a DSC thermogram on heating was measured for the

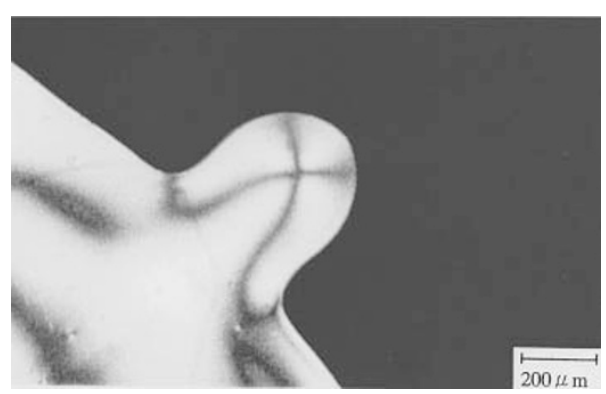

Figure 1. Polarizing optical photomicrograph of Schlieren texture for EDMB-10 quenched from the melt to $0{ }^{\circ} \mathrm{C}$, which was taken under crossed polarizers at $4{ }^{\circ} \mathrm{C}$. 


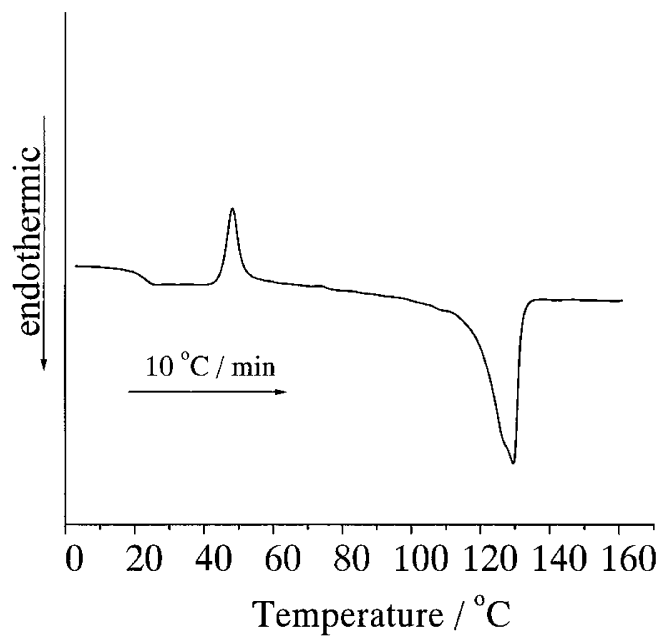

Figure 2. DSC thermograms of EDMB-10 quenched from the isotropic melt to $0^{\circ} \mathrm{C}$, which was measured at a heating rate of $10{ }^{\circ} \mathrm{C} \min ^{-1}$.

sample which was quenched in an aluminum pan from $140^{\circ} \mathrm{C}$ to $0^{\circ} \mathrm{C}$, as shown in Figure 2. An inflection of the thermogram due to the glass-LC transition, which may correspond to the $T_{\mathrm{g}}$ transition in this system, can be evidently observed at about $20^{\circ} \mathrm{C}$ and an exothermic peak probably assigned to cold crystallization appears at about $50{ }^{\circ} \mathrm{C}$. Moreover, a somewhat large endothermic curve whose top seems to split into two peaks is observed at about $110-135^{\circ} \mathrm{C}$ and these peaks should be assigned to the crystalline-nematic phase transition, which corresponds to melting, and the nematic-isotropic phase transition, which may be called isotropization, in the order of increasing temperature. Almost similar DSC phase transitions were observed on heating for main-chain thermotropic LC polyesters, which were quickly quenched below $T_{\mathrm{g}}$ from the isotropic melt, although the transition temperatures shifted to the higher temperature side compared to the case of EDMB-10, and such quenched samples were called as LC glass. ${ }^{9}$ Therefore, the phase transitions observed here also indicate the formation of the LC glassy phase of EDMB-10 by quenching described above. These are all the LC glasses quenched from the nematic phase and the LC glass was also produced from the smectic phase for certain LC polyesters. ${ }^{18}$

Figure 3 shows a wide-angle X-ray diffraction (WAXD) profile of the quenched sample, which was measured at room temperature immediately after quenching. For comparison, the profile of the isotropic melt obtained at $140^{\circ} \mathrm{C}$ is also shown in this figure. No sharp diffraction peaks ascribed to the presence of crystallites can be recognized for the quenched sample, but some broad diffraction peaks seem to appear at diffraction angles $(2 \theta)$ of about 7,18 , and 24 degrees. This fact suggests that some short-range ordering probably

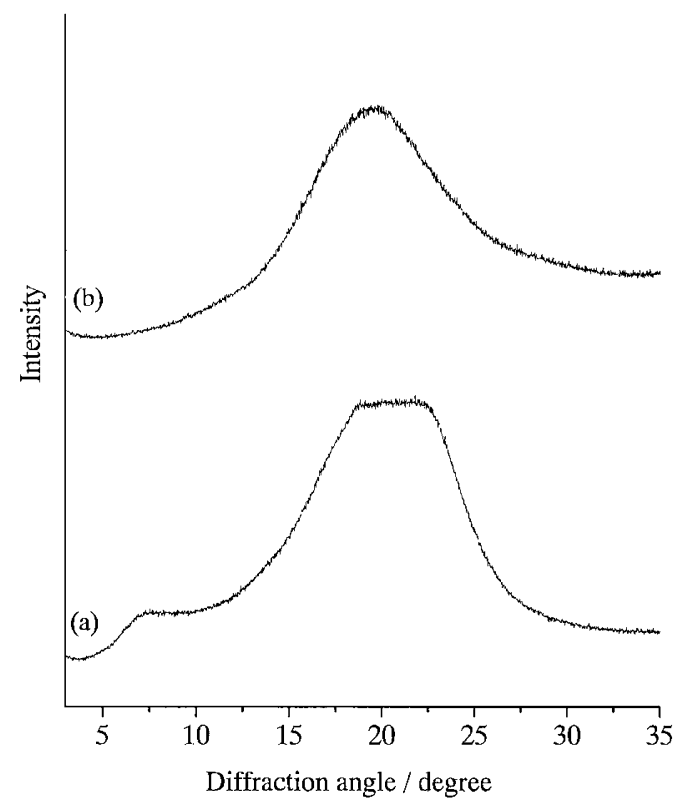

Figure 3. Wide-angle X-ray diffraction profiles of EDMB-10: (a) measured at room temperature immediately after quenched from the isotropic melt to $0{ }^{\circ} \mathrm{C}$, (b) measured at $140{ }^{\circ} \mathrm{C}$ in the isotropic molten state.

associated with orientation of the mesogen groups may be produced in the LC glassy phase, although no appreciably ordered structure seems to exist in the isotropic melt as shown in Figure 3(b). Such short-range ordering may be closely associated with the cold crystallization of another type of crystal form (form $\beta$ ) of EDMB-10 described below, which is significantly different from the crystal form ${ }^{8}$ (form $\alpha$ ) produced by slowly cooling from the isotropic melt through the nematic phase.

\section{Cold Crystallization from the LC Glassy Phase}

In the cooling process from the isotropic melt, it is almost impossible to characterize the crystallization process from the nematic phase at real time by WAXD or solid-state ${ }^{13} \mathrm{C}$ NMR spectroscopy because the nematic phase seems not to stably exist and the crystallization occurs very rapidly without significant delay at slower cooling rates. ${ }^{7,8}$ In contrast, cold crystallization from the LC glassy phase may be induced at a slower rate by annealing at appropriate temperatures above $T_{\mathrm{g}}$ and characterized in detail at real time by these analytical methods.

Figure 4 shows the WAXD profiles for the EDMB-10 samples crystallized from the LC glassy phase by annealing at $30^{\circ} \mathrm{C}$, which is about $10^{\circ} \mathrm{C}$ higher than $T_{\mathrm{g}}$, for $30 \mathrm{~min}$ and 24 weeks together with the profile of the sample crystallized by cooling at $1{ }^{\circ} \mathrm{C} \mathrm{min}{ }^{-1}$ from the isotropic melt through the nematic phase. Interestingly, the profiles of the samples crystallized from the LC glassy phase (Figure 4(a) and 4(b)) are evidently 


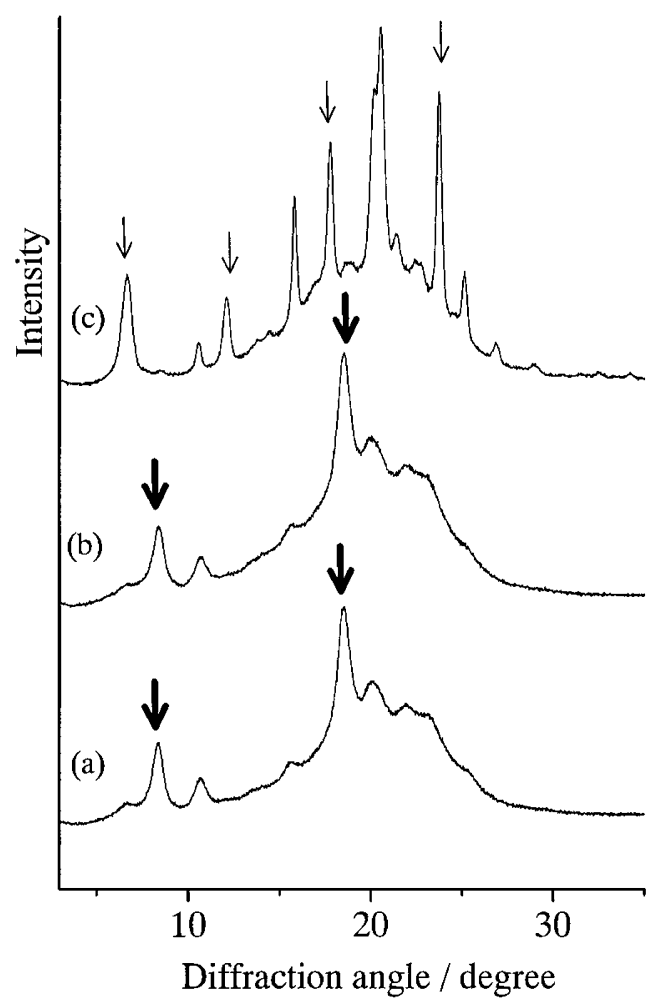

Figure 4. Wide-angle X-ray diffraction profiles of different EDMB-10 samples measured at room temperature: (a) crystallized from the LC glass to form $\beta$ at $30^{\circ} \mathrm{C}$ for $30 \mathrm{~min}$, (b) crystallized from the $\mathrm{LC}$ glass to form $\beta$ at $30^{\circ} \mathrm{C}$ for 24 weeks. (c) crystallized to form $\alpha$ by cooling from the isotropic melt through the nematic phase at a rate of $1^{\circ} \mathrm{C} \mathrm{min}^{-1}$.

different from the profile of the sample crystallized by slowly cooling from the melt through the nematic phase (Figure 4(c)). This fact indicates that a different type of crystal form is produced from the LC glassy phase while another crystal form is normally crystallized on cooling from the isotropic melt through the nematic phase. The former and latter crystal forms are hereafter referred to as form $\beta$ and form $\alpha$, respectively. Form $\alpha$ has remarkable diffraction peaks at $2 \theta=6.6$, $11.8,17.8$, and 23.6 degrees as indicated by thin arrows, while the peaks characteristic for form $\beta$ are observed at $2 \theta=8.4$ and 18.5 degrees as designated by thick arrows. The characterization of their detailed crystal structures is now in progress by using the uniaxially drawn samples. ${ }^{19}$ Since there is almost no change in intensity and line width of the diffraction profile between the samples shown in Figure 4 (a) and 4 (b), the cold crystallization to form $\beta$ seems to be terminated at $30^{\circ} \mathrm{C}$ within $30 \mathrm{~min}$ although crystallinity of form $\beta$ is rather lower than that of form $\alpha$. Therefore, the structural changes during the cold crystallization may be characterized at lower temperatures above $T_{\mathrm{g}}$ at real time by solid-state ${ }^{13} \mathrm{C}$ NMR spectroscopy because the crystallization will proceed at slower rates at such temperatures.

Figure 5 shows $\mathrm{CP} / \mathrm{MAS}{ }^{13} \mathrm{C}$ NMR spectra of dif-

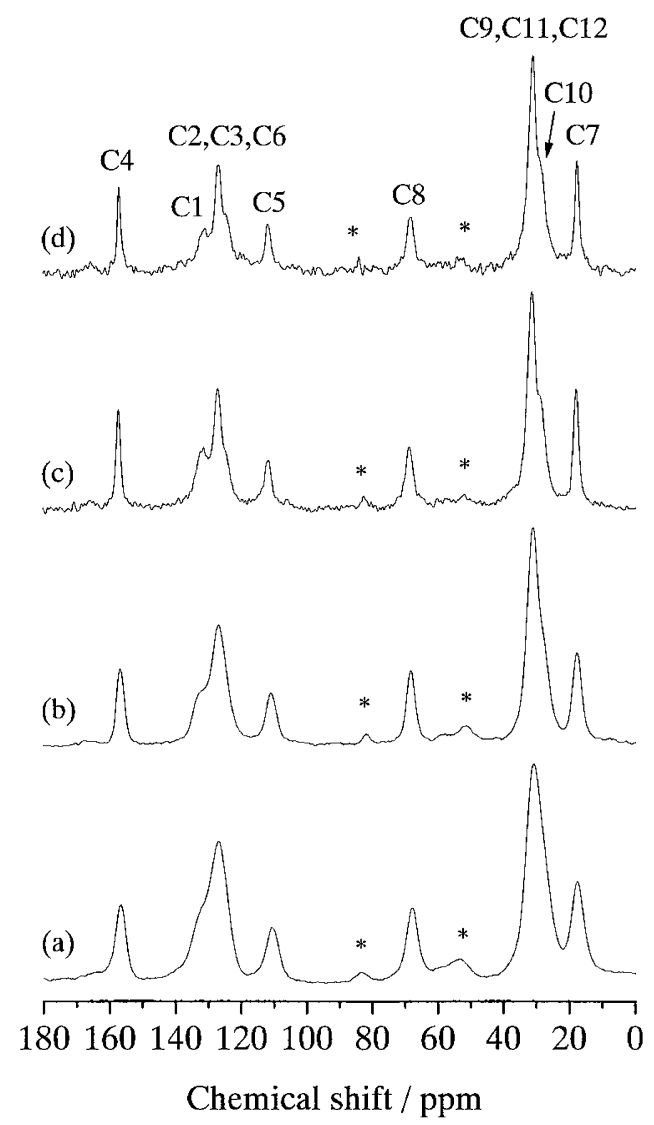

Figure 5. $\mathrm{CP} / \mathrm{MAS}{ }^{13} \mathrm{C}$ NMR spectra of different EDMB-10 samples: (a) measured at $-50^{\circ} \mathrm{C}$ for the LC glass immediately after quenched from the isotropic melt to $0^{\circ} \mathrm{C}$, (b) measured at $0{ }^{\circ} \mathrm{C}$ for the $\mathrm{LC}$ glass stored at $0^{\circ} \mathrm{C}$ for $175 \mathrm{~d}$, (c) measured at room temperature for the sample crystallized to form $\beta$ at room temperature for $48 \mathrm{~d}$, (d) measured at room temperature for the sample crystallized to form $\beta$ at room temperature for $145 \mathrm{~d}$. * indicates a spinning sideband.

ferent EDMB-10 samples in the LC glassy state or in the crystallized state from the LC glassy phase. The spectrum in the LC glassy phase (Figure $5(\mathrm{a})$ ), which was measured at $-50{ }^{\circ} \mathrm{C}$ immediately after quenched from the isotropic melt to $0{ }^{\circ} \mathrm{C}$, seems almost structureless and each resonance line is rather broad without any sharp contribution. It was also confirmed that this sample gave almost the same WAXD profile as for the noncrystalline, quenched sample shown in Figure 3 (a). A similar structureless NMR spectrum is also obtained for the sample left at $0{ }^{\circ} \mathrm{C}$ for $175 \mathrm{~d}$ as shown in Figure $5(\mathrm{~b})$, although slight changes in line width are recognized in the resonance lines around 130 and $30 \mathrm{ppm}$. In contrast, it is clearly found from Figure 5 (c) that each resonance line is significantly narrower for the sample kept at room temperature for $48 \mathrm{~d}$ after quenched from the isotropic melt to $0{ }^{\circ} \mathrm{C}$. Moreover, further narrowing occurs for the sample (Figure 5 (d)) kept at room temperature for $145 \mathrm{~d}$ and a separate $T_{1}^{\mathrm{C}}$ decay curve analysis revealed that there exist two components with $T_{1}^{\mathrm{C}}=0.4$ and $2.2 \mathrm{~s}$ in the $\mathrm{CH}_{2}$ resonance 


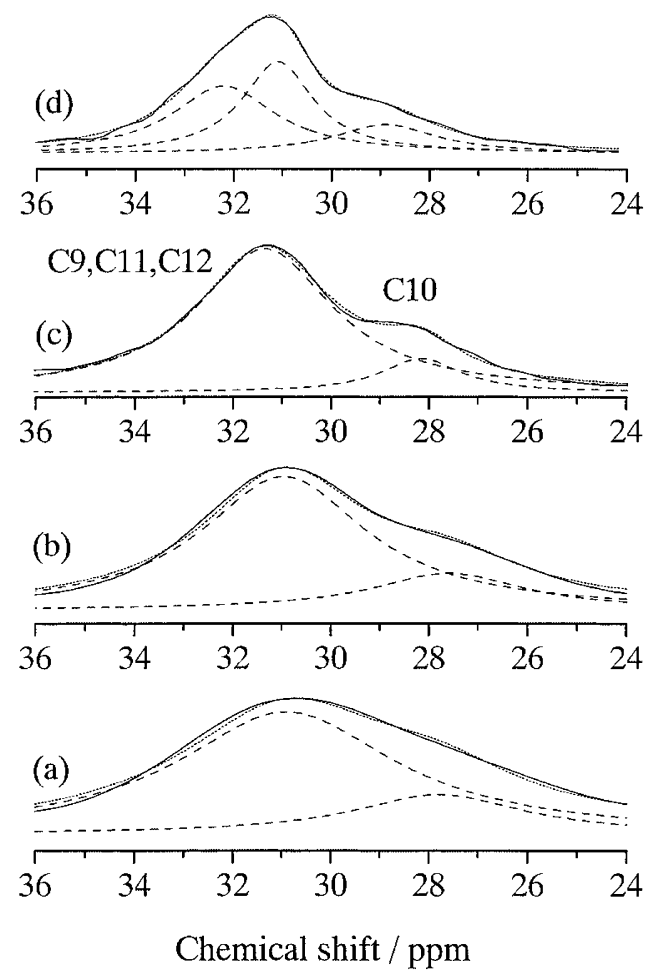

Figure 6. Lineshape analyses of $\mathrm{CP} / \mathrm{MAS}{ }^{13} \mathrm{C}$ NMR spectra in the methylene region for the different EDMB-10 samples: (a)-(c) the same spectra as shown in Figure 5 (a)-(c), respectively, (d) the spectrum of the component with a longer $T_{1}^{\mathrm{C}}$ which was selectively observed for the sample shown in Figure 5 (d) by the CPT1 pulse sequence ${ }^{14}$ setting the $T_{1}^{\mathrm{C}}$ decay time to $2 \mathrm{~s}$.

lines for this sample whereas only single component with $T_{1}^{\mathrm{C}}=0.5 \mathrm{~s}$ is observed for the sample kept at room temperature for $48 \mathrm{~d}$. Nevertheless, similar WAXD profiles indicating the existence of the form $\beta$ crystallites were obtained for both samples kept at room temperature for 48 and $145 \mathrm{~d}$. Therefore, the component with $T_{1}^{\mathrm{C}}=2.2 \mathrm{~s}$ cannot be simply assigned to the crystalline component.

To obtain further information about the structure of the samples crystallized at room temperature, line shape analyses have been performed for the $\mathrm{CH}_{2}$ resonance lines assigned to the $\mathrm{C} 9-\mathrm{C} 12$ carbons for the respective samples shown in Figure 5 by assuming each constituent line to be a Lorentzian curve as shown in Figure 6. Although the sample left at room temperature for $145 \mathrm{~d}$ has two components with different $T_{1}^{\mathrm{C}}$ values as described above, only the spectrum of the longer $T_{1}^{\mathrm{C}}$ component is shown in this figure because the spectrum of the shorter $T_{1}^{\mathrm{C}}$ component is almost the same as that of the sample left at room temperature for $48 \mathrm{~d}$. Here, the former spectrum was selectively observed by using the CPT1 pulse sequence ${ }^{14}$ with a $T_{1}^{\mathrm{C}}$ decay time of $2 \mathrm{~s}$. Except for the spectrum shown in Figure 6 (d), the $\mathrm{CH}_{2}$ resonance lines of each sample can be well resolved into two Lorentzian curves that should be assigned to the $\mathrm{C} 9,11,12$ carbons and the $\mathrm{C} 10$ carbons from the downfield side. In particular, it should be noted here that much clearer separation into the two lines as observed in Figure 6(c) is due to the crystallization to form $\beta$ slowly occurring at room temperature. Moreover, another new line appears at $32.2 \mathrm{ppm}$ for the sample left at room temperature for $145 \mathrm{~d}$, as evidently seen in Figure 6(d). The same downfield line, which indicates the formation of the trans-rich conformation for the $\mathrm{CH}_{2}$ sequence, ${ }^{6,7,13,20}$ was also confirmed for the sample with much higher crystallinity of form $\beta$, whose preparation method will be described later. These facts imply that the formation of form $\beta$ at room temperature proceeds at two stages probably through the conformational rearrangement of the spacer $\mathrm{CH}_{2}$ sequences. However, such a conformational change may hardly affect the three-dimensional crystal lattices basically formed by the mesogen units because there is no appreciable difference in WAXD profiles in the two stages. The detailed conformational characterization of form $\beta$ and the LC glassy phase is now in progress ${ }^{21}$ in relation to form $\alpha$ previously reported. ${ }^{7,8}$

\section{Possible Formation of the Stable Nematic Phase on Heating}

Next, we examine the cold crystallization from the LC glassy phase at higher temperatures up to the melting temperature to find the conditions to induce better crystallization of form $\beta$. Moreover, through this experiment, we also evaluate the possibility of the existence of the stable nematic phase in the heating process. WAXD samples for this purpose were prepared by annealing the LC glassy films in a silicone bath controlled at each temperature for $30 \mathrm{~min}$ and then immediately quenching them to $0^{\circ} \mathrm{C}$. Figure 7 shows WAXD profiles measured at room temperature for the samples thus annealed at $120-138^{\circ} \mathrm{C}$ and then quenched to $0{ }^{\circ} \mathrm{C}$. It is clearly seen that the diffraction peaks assignable to form $\beta$ are increased in both intensity and resolution with increasing annealing temperature up to $130{ }^{\circ} \mathrm{C}$ and the highest crystallinity can be obtained by annealing at $130^{\circ} \mathrm{C}$. Furthermore, when the sample was kept at $130^{\circ} \mathrm{C}$ for about $2 \mathrm{~d}$ after such heating, almost the same WAXD profile as that shown in Figure 7 (c) was also obtained by quenching that sample to $0^{\circ} \mathrm{C}$. This fact suggests that the stable nematic phase may be allowed to exist at $130^{\circ} \mathrm{C}$ on heating in this system and better crystallization of form $\beta$ may be induced by quenching from such a stable nematic phase to $0{ }^{\circ} \mathrm{C}$. It would be, therefore, possible to note that higher crystallinity of form $\beta$ may be obtained by the crystallization from the stable nematic phase compared to the case of the crystallization from the supercooled nematic phase which 


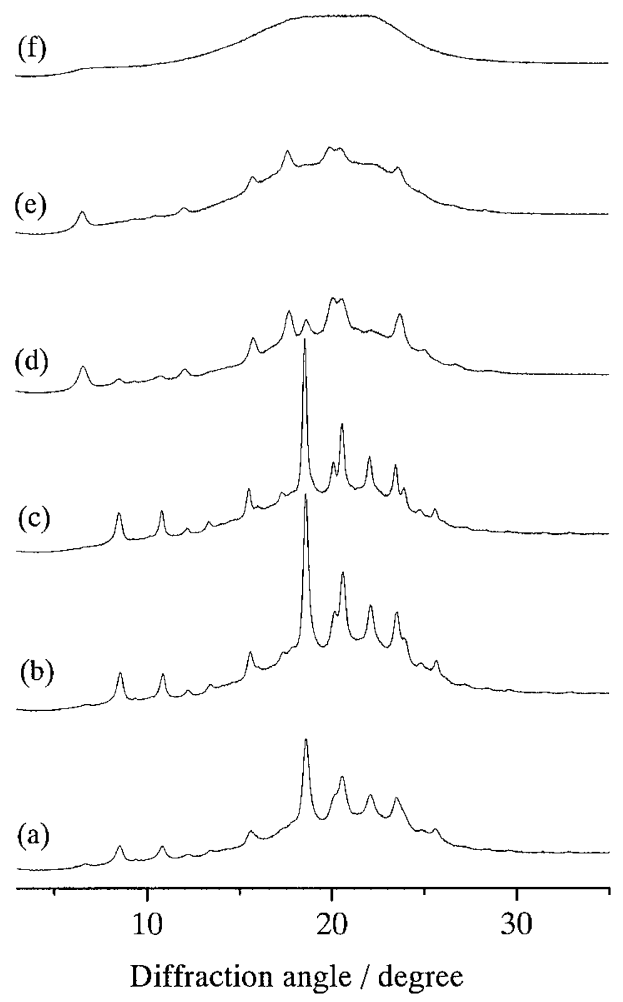

Figure 7. Wide-angle X-ray diffraction profiles measured at room temperature for the different EDMB-10 samples which were quenched to $0{ }^{\circ} \mathrm{C}$ after annealed for $30 \mathrm{~min}$ at different temperatures by immersing the LC glassy films into a silicone bath: (a) $120^{\circ} \mathrm{C}$, (b) $126^{\circ} \mathrm{C}$, (c) $130{ }^{\circ} \mathrm{C}$, (d) $132{ }^{\circ} \mathrm{C}$, (e) $134^{\circ} \mathrm{C}$, and (f) $138^{\circ} \mathrm{C}$.

appears at temperatures between $T_{\mathrm{g}}$ and $T_{\mathrm{m}}$. Direct evidence of the appearance of the stable nematic phase on heating will be obtained by temperature-jump polarizing optical microscopy or X-ray diffractometry in near future. It should be also noted here that no significant change in folded-chain structure may occur in the stable nematic phase at lease in about $2 \mathrm{~d}$ unlike the case of the smectic $\mathrm{H}$ phase ${ }^{22}$ because WAXS profiles of the crystallized samples were not appreciably altered in that period as described above.

Figure 7 also demonstrates another interesting experimental result of the formation of form $\alpha$ in the heating process, although this crystal form is ordinarily produced by slowly cooling from the isotropic melt through the nematic phase as frequently described above: Somewhat broader diffraction peaks ascribed to form $\alpha$ are observed by annealing at $132-134{ }^{\circ} \mathrm{C}$ and then quenching to $0^{\circ} \mathrm{C}$, as shown in Figure 7 (d) and 7 (e). Since such crystallization is presumed to occur by quenching to $0{ }^{\circ} \mathrm{C}$, another type of stable nematic phase to produce form $\alpha$ on quenching may exist in this temperature range. The formation of the form $\alpha$ and form $\beta$ crystals in the heating process will be discussed in more detail by using the Gibbs free energy-temperature dia$\operatorname{gram}^{3,23}$ after the completion of the characterization of both crystal forms and the noncrystalline components

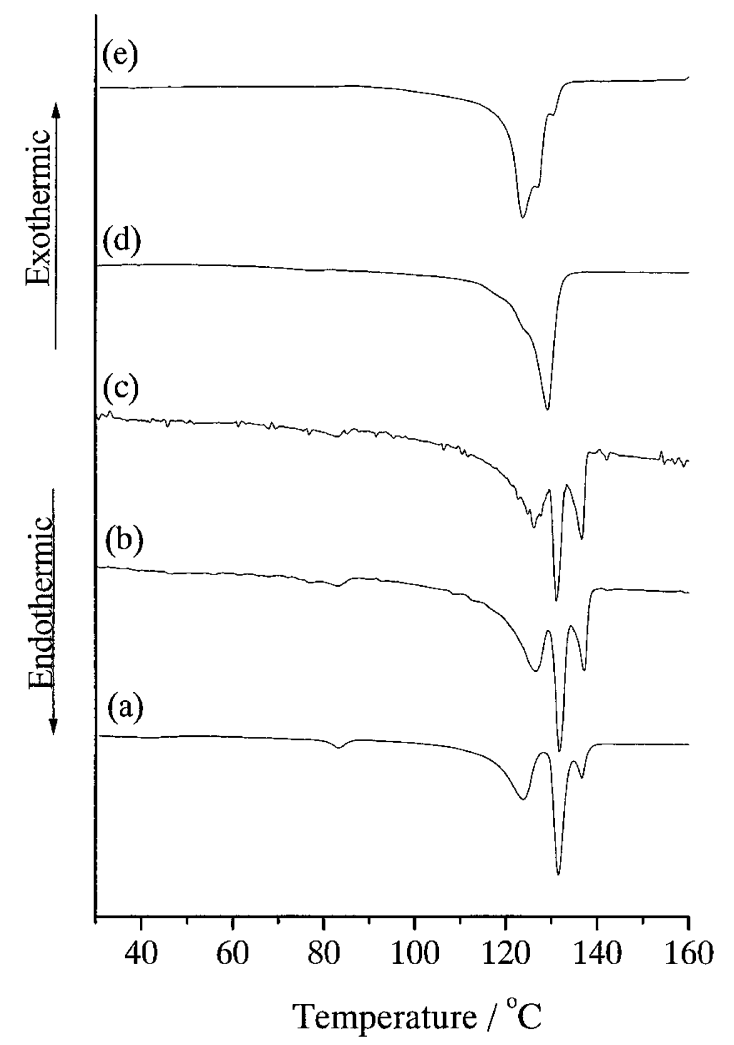

Figure 8. DSC thermograms of the form $\beta$ (a)-(c) and form $\alpha$ (d), (e) samples at various heating rates. The form $\alpha$ samples for (d) and (e) were prepared by cooling from the isotropic melt at cooling rates of 10 and $1{ }^{\circ} \mathrm{C} \mathrm{min}^{-1}$, respectively: (a) $10^{\circ} \mathrm{C} \mathrm{min}^{-1}$, (b) $5^{\circ} \mathrm{C} \mathrm{min}^{-1}$, (c) $2{ }^{\circ} \mathrm{C} \mathrm{min}^{-1}$, (d) $10^{\circ} \mathrm{C} \mathrm{min}^{-1}$, and (e) $10^{\circ} \mathrm{C} \mathrm{min}^{-1}$.

included in the crystallized samples as supercooled LC components by solid-state ${ }^{13} \mathrm{C}$ NMR and WAXD methods.

\section{Additional Phase Transitions Associated with Form $\alpha$ and Form $\beta$}

Since the form $\beta$ sample with higher crystallinity was obtained by annealing at $130^{\circ} \mathrm{C}$ and successively quenching to $0{ }^{\circ} \mathrm{C}$ as described above, DSC thermograms on heating have been measured for this sample at different heating rates as shown in Figure 8. For comparison, the thermograms for the form $\alpha$ sample which was prepared by cooling at a rate of 1 or $10^{\circ} \mathrm{C} \mathrm{min}^{-1}$ from the isotropic melt through the nematic phase, are also shown in this figure. Interestingly, two endothermic peaks additionally appear at about 83 and $137^{\circ} \mathrm{C}$ for the form $\beta$ sample compared to the case of the LC glassy sample shown in Figure 2 and the main two peaks ascribed to melting and isotropization are much more clearly separated with each other in this sample. The former small peak at about $83{ }^{\circ} \mathrm{C}$ may be due to partial melting or some kind of crystal-crystal transition, for example the form $\beta \rightarrow$ form $\alpha$ transition, because it is an endothermic process. In addition, the relative intensity of another additional peak at about $137^{\circ} \mathrm{C}$ 


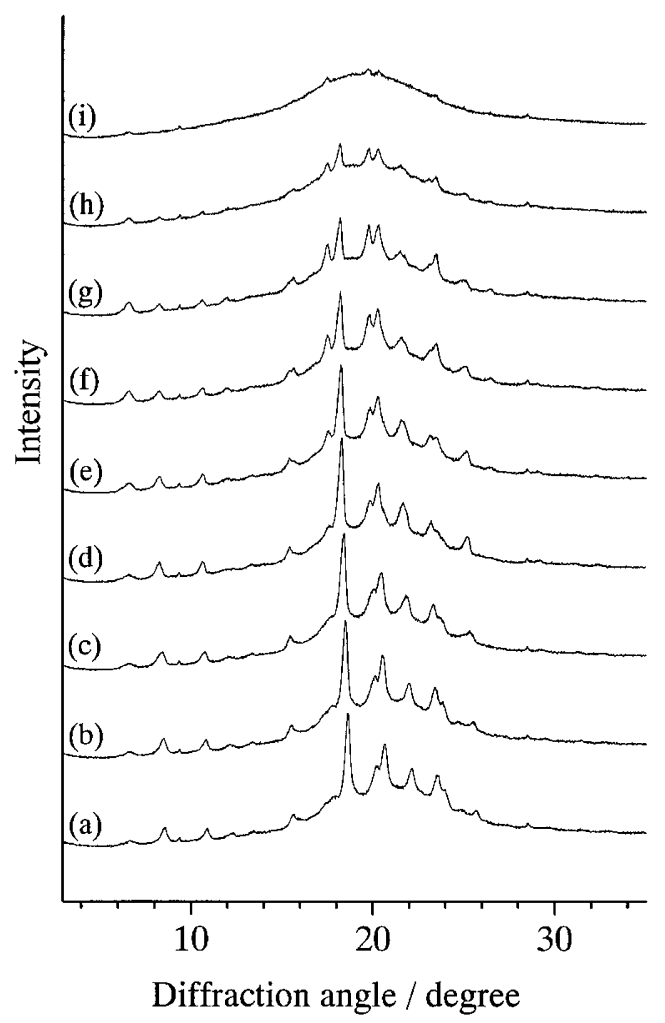

Figure 9. Wide-angle X-ray diffraction profiles measured for the form $\beta$ sample with high crystallinity at different temperatures upon heating: (a) $30^{\circ} \mathrm{C}$, (b) $60^{\circ} \mathrm{C}$, (c) $80^{\circ} \mathrm{C}$, (d) $100^{\circ} \mathrm{C}$, (e) $110^{\circ} \mathrm{C}$, (f) $120^{\circ} \mathrm{C},(\mathrm{g}) 130^{\circ} \mathrm{C},(\mathrm{h}) 135^{\circ} \mathrm{C}$, and (i) $140^{\circ} \mathrm{C}$.

is found to appreciably increase with decreasing heating rate.

To make the assignment of the peak at about $83{ }^{\circ} \mathrm{C}$ and to also obtain additional information about another peak at about $137^{\circ} \mathrm{C}$, WAXD profiles have been obtained at different temperatures on heating for the same form $\beta$ sample with higher crystallinity as used for the DSC measurements shown in Figure 8 (a)-(c). Figure 9 shows WAXD profiles thus obtained at different temperatures on heating. Most of prominent diffraction peaks observed below $100^{\circ} \mathrm{C}$ are ascribed to the form $\beta$ crystallites but broader diffraction peaks assignable to form $\alpha$ are also recognized at diffraction angles of about 7, 18, and 24 degrees in this sample. The latter three peaks become sharper above $100^{\circ} \mathrm{C}$ and their intensities are markedly increased with increasing temperature up to $130^{\circ} \mathrm{C}$. This fact implies that form $\alpha$ may be grown to larger-size crystallites by annealing or may be newly crystallized on heating after melting of the smaller-size crystallites in the temperature region of about $100-130^{\circ} \mathrm{C}$. Moreover, a part of form $\alpha$ thus prepared seems to remain at $140^{\circ} \mathrm{C}$ even after the form $\beta$ crystallites are melted as seen in Figure 9(i). Similar form $\alpha$ crystallites seem to be also produced for the form $\alpha$ sample which was prepared by slowly cooling from the isotropic melt through the nematic phase,

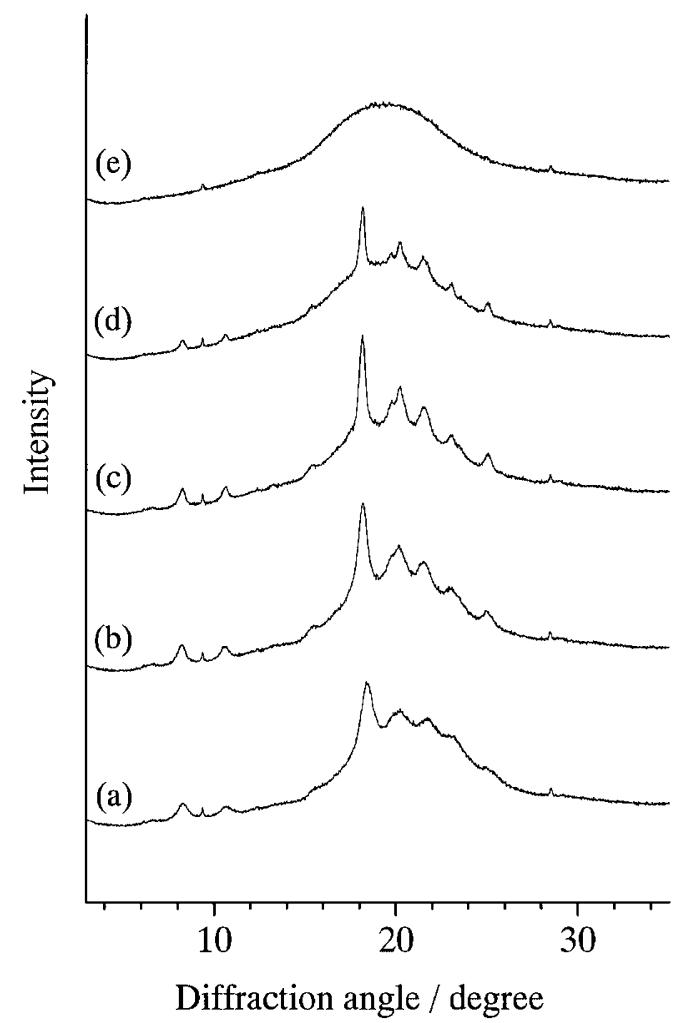

Figure 10. Wide-angle X-ray diffraction profiles measured for the LC glassy films at different temperatures upon heating: (a) $90^{\circ} \mathrm{C}$, (b) $110^{\circ} \mathrm{C}$, (c) $130^{\circ} \mathrm{C}$, (d) $135^{\circ} \mathrm{C}$, and (e) $140{ }^{\circ} \mathrm{C}$.

because another DSC endothermic peak appears at a higher temperature at a slower cooling rate as shown in Figure 8 (e). Therefore, the small endothermic peak appearing at about $83{ }^{\circ} \mathrm{C}$ in Figure 8 should not be assigned to the form $\beta \rightarrow$ form $\alpha$ transition but may be ascribed to melting of small-size form $\alpha$ crystallites. In particular, it should be noted here that the form $\alpha$ crystallites additionally produced on heating have a higher melting temperature than the normal form $\alpha$ crystals produced on cooling and the nematic phase seems not to appear after melting because the Schlieren texture was not observed at such a high temperature by polarizing optical microscopy. Moreover, Figures 8 (a)-(c) indicate that the production of such form $\alpha$ crystallites is much enhanced with the decrease in heating rate because the intensity of the endothermic peak at about $137^{\circ} \mathrm{C}$ is evidently increased with decreasing heating rate.

For comparison, Figure 10 shows WAXD profiles obtained at different temperatures on heating for the LC glassy sample without any annealing at higher temperatures unlike the case shown in Figure 9. In this experiment, the LC glassy sample was quickly set on the WAXD apparatus at room temperature immediately after quenched from the melt to $0{ }^{\circ} \mathrm{C}$ and then WAXD profiles were successively obtained at different temperatures on heating. It took about $1 \mathrm{~h}$ to measure each 
WAXD profile including the time required for setting each temperature. In this case no diffraction peaks assigned to form $\alpha$ are found to appear at diffraction angles of about 7, 18, and 24 degrees unlike the case shown in Figure 9 and any type of form $\alpha$ with a higher melting temperature seems not to be produced in this system. Therefore, such small-size form $\alpha$ crystallites observed below about $100^{\circ} \mathrm{C}$ for the form $\beta$ sample shown in Figure 9 may happen to be produced by quenching the sample from 130 to $0^{\circ} \mathrm{C}$ after the LC glassy sample is annealed at $130^{\circ} \mathrm{C}$. The additional crystallization of form $\alpha$ observed at $100-130^{\circ} \mathrm{C}$ in Figure 9 will be also closely associated with the melting of the small-size form $\alpha$ crystallites because no crystallization of form $\alpha$ is observed on heating in Figure 10. Finally it should be noted that these incidential phase transitions may be due to the too much narrow temperature region for the stable nematic phase appearing on heating in this system; a small part of the sample would be in another phase even if most part could be in the stable nematic phase.

\section{CONCLUSIONS}

We have investigated the formation of the LC glassy phase and the crystallization or the phase transitions associated with that phase for thermotropic LC polyether (EDMB-10) mainly using DSC, WAXD, and solidstate ${ }^{13} \mathrm{C}$ NMR spectroscopy and the following conclusions have been obtained through these investigations:

(1) DSC heating thermograms and WAXD profiles have revealed that the LC glassy phase is really formed by quenching the EDMB-10 sample from the isotropic melt to ice-water. Such formation of the LC glass is confirmed to be due to the fact that the liquid crystallization temperature of EDMB-10 stays almost constant irrespective to the cooling rate whereas the crystallization temperature is rapidly decreased with increasing cooling rate as previously reported.

(2) The cold crystallization from the LC glassy phase is found to occur above the transition temperature from the LC glassy phase to the supercooled LC phase, which corresponds to $T_{\mathrm{g}}$ in this system, and a new type of crystal form referred to as form $\beta$ is produced, which significantly differs in structure from another crystal form called form $\alpha$ that is ordinarily crystallized on cooling from the isotropic melt through the nematic phase. Moreover, form $\beta$ crystallites may be grown closely above $T_{\mathrm{g}}$ at two stages and the spacer conformation becomes richer in trans fraction at the later stage without any significant change in the crystal lattice mainly composed of the mesogen units.

(3) It is found by WAXD measurements that the high- est crystallinity of form $\beta$ can be obtained when the LC glass is annealed at $130{ }^{\circ} \mathrm{C}$ for 30 min-about $2 \mathrm{~d}$ immediately after prepared and then it is quickly quenched to $0^{\circ} \mathrm{C}$. This fact implies that the stable nematic phase producing form $\beta$ crystallites will be formed on rapid heating from the LC glass phase. In addition, form $\alpha$ is also crystallized in the heating process by quenching to $0{ }^{\circ} \mathrm{C}$ after annealing the LC glass at $132-134^{\circ} \mathrm{C}$, leading to the suggestion that the stable nematic phase producing form $\alpha$ crystallites may also appear on heating at the temperature range of $132-134{ }^{\circ} \mathrm{C}$ for EDMB- 10 .

(4) It is suggested for the form $\beta$ sample with the highest crystallinity by the DSC and WAXD measurements in the heating process that partial melting and re-crystallization of form $\alpha$ may additionally occur on heating since this form happen to be also produced in the sample probably due to the limitation in setting of experimental conditions.

Acknowledgment. This work was supported by Grant-in-Aid for Scientific Research (No. 12450384) from the Ministry of Education, Culture, Sports, Science and Technology, Japan.

\section{REFERENCES}

1. A. Ciferri Ed., "Liquid Crystallinity in Polymers. Principles and Fundamental Properties", VCH Publichers, New York, N.Y., (1991).

2. A. I. Isayev, T. Kyu, and S. Z. D. Cheng, Eds., "LiquidCrystalline Polymer Systems. Technological Advances", ACS Symp. Series 632, Am. Chem. Soc., Washington DC, (1996).

3. P. J. Collings and J. S. Patel, Eds., "Handbook of Liquid Crystal Research", Oxford Univercity Press, New York, Oxford (1997).

4. I. M. Ward Ed., "Structure and Properties of Oriented Polymers", Chapman \& Hall, London, Glasgow, New York, Tokyo, Melbourne, Chennai (1997).

5. T.-S. Chung Ed., "Thermotropic Liquid Crystal Polymers", Technomic, Lancaster, (2001).

6. H. Ishida, H. Kaji, and F. Horii, Macromolecules, 30, 5799 (1997). Related references of liquid crystalline polymers are therein.

7. H. Ishida and F. Horii, Macromolecules, 34, 7751 (2001).

8. M. Murakami, H. Ishida, M. Miyazaki, H. Kaji, and F. Horii, Macromolecules, 36, 4160 (2003).

9. B. Wunderlich and J. Grebowicz, in "Liquid Crystals Polymers II/III", M. Gordon and N. A. Plate Eds., Adv. Polym. Sci., Springer-Verlag, Belin, Heidelberg, New York, Tokyo, 1984, p. 1.

10. H. Ishida and F. Horii, Macromolecules, 35, 5550 (2002).

11. Y. Ohira, F. Horii, and T. Nakaoki, Macromolecules, 34, 1655 (2001).

12. K. Kuwabara, H. Kaji, M. Tsuji, and F. Horii, Macromolecules, 33, 8520 (2000).

13. K. Masuda and F. Horii, Macromolecules, 31, 5810 (1998). 
14. D. A. Torchia, J. Magn. Reson., 30, 613 (1978).

15. K. L. Kaplan, F. A. Bovey, and M. N. Cheng, Anal. Chem., 47, 1703 (1975).

16. S. Saito, Y. Moteki, M. Nakagawa, F. Horii, and R. Kitamaru, Macromolecules, 23, 3257 (1990).

17. H. Tsuji, F. Horii, M. Nakagawa, Y. Ikada, H. Odani, and R. Kitamaru, Macromolecules, 25, 4114 (1992).

18. M. Tokita, K. Osada, and J. Watanabe, Polym. J., 30, 589 (1998).

19. M. Ooyama, T. Yamamoto, K. Nozaki, and F. Horii, Polym.
Prepr., Jpn., 52, 549 (2003).

20. A. E. Tonelli, "NMR Spectroscopy and Polymer Microstructure: The Conformational Connection”, VCH Publishers, New York, N.Y., 1989.

21. M. Murakami, H. Ishida, and F. Horii, Polym. Prepr., Jpn., 51, 572 (2002).

22. M. Tokita, K. Osada, M. Yamada, and J. Watanabe, Macromolecules, 31, 8590 (1998).

23. A. Keller and S. Z. D. Cheng, Polymer, 39, 4461 (1998). 